\title{
Başkale Bölgesi’nin (Van) Jeolojik ve Jeomorfolojik Öğeleri
}

\author{
Geological and Geomorphological Elements of Başkale Region, Van
}

\author{
Azad SAĞLAM SELÇUK ${ }^{1}$, Halil ZORER ${ }^{2}$

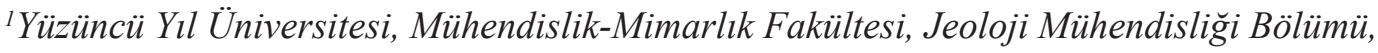 \\ 65080 Tuşba/Van (azadsaglam@gmail.com)

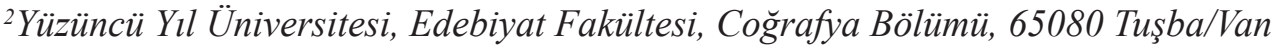 \\ (zorer-halil@hotmail.com)
}

ÖZ

Başkale Bölgesi, Basra Havzasında yer almaktadır. Bölgede yerleşmiş, gelişmiş ve yok olmuş birçok medeniyet ile halen süren yaşam faaliyetlerini etkileyen, kontrol eden en önemli etkenlerden birisi de bölgenin jeoloji ile jeomorfolojisidir. Başkale bölgesinde, farklı yer süreçleri sonucunda gelişmiş birçok jeolojik miras öğesini gözlemlemek mümkündür. Bunlardan bazıları tektonik bazıları ise volkanik kökenlidir. Havzada bulunan jeolojik miras üyelerinin çoğu traverten oluşumları ile ilgilidir. Özellikle, travertenlerin çökelme süreçlerine bağlı olarak aktif olarak gelişen sırt ve teras tipi travertenler bölgenin birçok alanında izlenebilmektedir.

Başkale Bölgesinin kuzeydoğusunda Neojen-Kuvaterner volkanik ürünlerin oluşturduğu Vanadokya Volkanik Alanı (VVA) yer alır. Yaklaşık olarak 55 km²'lik alanı kaplayan VVA'da 1700'den fazla peri bacası oluşumu bulunmaktadır. Bölgenin kuzey kesiminde yaygın olarak görülen bu volkanizma jeomorfolojiyi kontrol eden önemli faktörlerden biridir.

Bu çalışmada, Başkale Bölgesinde gözlemlenen jeolojik miras niteliği taşıyan oluşumlar, bölge jeolojisi ve stratigrafisi içerisindeki konumları ile eski medeniyetlere ev sahipliği yapmış olan kültürel miras öğeleri tanitılacaktır.

Anahtar Kelimeler: Başkale, jeolojik miras, traverten, volkanizma.

\section{ABSTRACT}

Basskale region is located in the basin of Lake Van. The geology and geomorphology of the area are one of the most important factors in controlling it settled in the region with many extinct civilization developer and ongoing activities of life. Advanced many different places as a result of geological processes inherited 
members can be apparent at Başkale Region. Some of these sites are formed by volcanic or tectonic processes where the most are of travertine formations. The fissure ridge and terrace type travertines are clearly observed in this region.

Neogene-Quaternary volcanic rocks forming the Vanadocia Volcanic Complex (VVA) are located in the northeast of Başkale region. VVA is covers an area of $55 \mathrm{~km}^{2}$ and express a vast badland topography with countless fairy chimneys.

In this study, geology and stratigraphy within the Başkale region will be explained and related with the geoheritage and cultural heritage sites of ancient civilizations.

Keywords: Başkale region, geoheritage, travertine, volcanism.

\section{GİRIŞ}

Doğu Anadolu Bölgesi, Anadolu ve Arap Levhalarının çarpışmaları sonucunda gelişen karmaşık bir tektonik yapıya sahiptir. Geç Miyosen döneminde gerçekleşen bu çarpışma sonucunda, bölgedeki kıta kabuğu kalınlaşmış ve bölgesel bir yükselme gözlenmiştir (Şengör ve Kidd, 1979; Şengör ve Y1lmaz, 1981; Dewey vd.. 1986; Şaroğlu ve Yılmaz, 1986; Yılmaz vd., 1987; Koçyiğit vd., 2001). İnceleme alan1, GPS hız ve yönleri kullanılarak gerçekleştirilen blok modellerde (Relinger vd., 2006) Türkiyeİran Platosu bloğu içerisinde yer almaktadır. $\mathrm{Bu}$ plato, kuzeyinde Çaldıran Fayı güneyinde ise Bitlis Sütur Zonu tarafından sınırlanmakta ve saat yönünün tersine bir rotasyon gerçekleşmektedir (Gürsoy ve diğ. 2009). Bölge, Doğu Anadolu Sıkışmalı Tektonik Bloğu (DAST) içerisinde tanımlanmaktadır (Şekil 1).

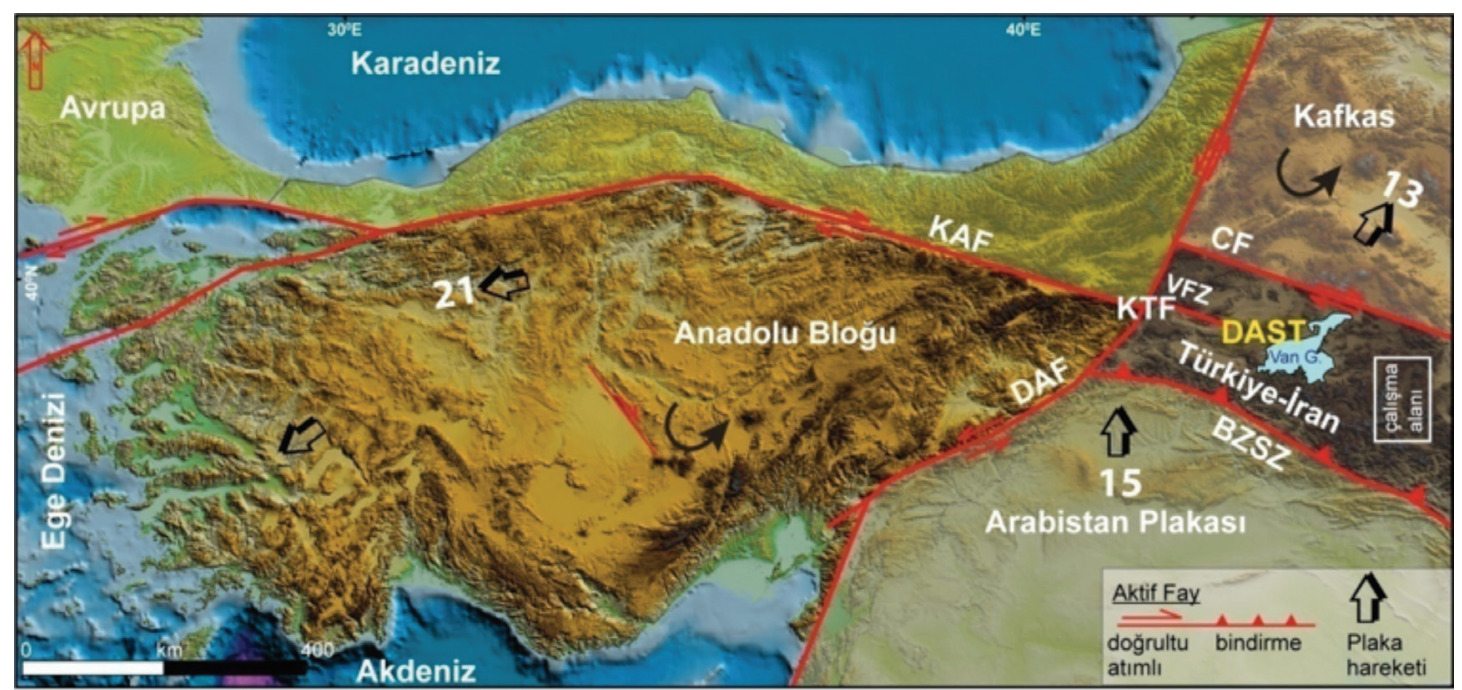

Şekil 1. Çalışma alanının Türkiye'nin neotektonik çatısı içerisindeki konumu (Blok sınırları Reilinger vd., 2006; Djomour vd., 2011'den alınmıştır) (KAFZ: Kuzey Anadolu Fay Zonu, DAFZ: Doğu Anadolu Fay zonu, BZSZ: Bitlis-Zagros Sütur Zonu, CF: Çaldıran Fayı, KTF: Karlıova Üçlü Eklemi, VFZ, Varto Fay Zonu, KDAF: Kuzeydoğu Anadolu Fayı; DAST: Doğu Anadolu Sıkışmalı Tektonik Bloğu).

Figure 1. Location of the study area and block boundaries from Reilinger et al. 2006 and Djomour et al. 2011 (KAFZ: North Anatolian Fault, DAFZ: East Anatolian Fault, BZSZ: Bitlis-Zagros Suture Zone, CF: Çaldıran Fault, KTF: Karlıova Triple Junction, VFZ, Varto Fault Zone, KDAF: Northeast Anatolian Fault; DAST: East Anatolian High Plateau). 
Doğu Anadolu Bölgesi, Avrasya ve Arabistan Levhaları arasında K-G yönünde sıkışmakta ve bu sıkışma rejimine bağlı olarak bölgede KD-KB gidişli doğrultu atımlı faylar, D-B gidişli ters faylar ve K-G gidişli normal faylar gelişmektedir (Şengör ve Kidd, 1979; Şengör ve Y1lmaz, 1981; Dewey vd., 1986; Şaroğlu ve Yılmaz, 1986; Yılmaz vd., 1987; Koçyiğit vd., 2001). Geç Miyosen'de karasal ortama dönüşen bölge, tektonizmanın ilerlemesi ile doğu-batı yönünde uzanan plato karakterli yükselim alanları ve dağ arası karasal havzalardan oluşan günümüz görünümünü kazanmıştır (Ateş vd., 2007). Pliyosen sonundan günümüze etkin olan tektonizma ve yaygın volkanizma bölgenin yükselerek kubbe morfolojisine sahip olmasını ve günümüz akarsu ağının kurulmasını sağlamıştır (Şengör vd., 2003).

Van İli’nin güneydoğusunda yer alan Başkale Havzası (Şekil 1), morfolojik olarak kuzey-güney doğrultulu yüksek dağ dizileri arasındaki bir vadi olarak tanımlanabilir. Havza, batıda Başkale (3668 m) ve Mengene Dağları ile Van Gölü Havzası'ndan ayrılırken, doğuda
Yiğit (3468 m) ve Doğanlı Dağları ile sınırlanır ve Büyük Zap Suyu'nun kuzey kolu olan Çı̆ğl Suyu tarafından akaçlanır. Havza güneyinde Büyük Zap'la birleşen Çı̆̆lı Suyu, Irak sınırları içerisinde Dicle Nehri ile birleşir ve Şattül-arapta Basra Körfezi'ne dökülür. Çığlı Suyu'nun aktığı vadi, tabanlı bir vadidir. Bununla birlikte uzanımı boyunca derin ve dar boğazlar da gözlemlenir.

Başkale Havzası içerisinde, farklı yer süreçleri sonucunda gelişmiş birçok jeolojik miras üyesini görmek mümkündür (Şekil 2). Bunlardan bazıları tektonik, bazıları ise volkanik kökenlidir. Havzanın kuzeydoğusunda, Yavuzlar köyünde volkanik kayaçlardan oluşan Peribacaları (Vanadokya) yer alır. Havzanın güneyinde ise yaygın traverten oluşumlarını görmek mümkündür. Bunlardan bölgede en iyi bilinenleri Dereiçi Köyü'nde bulunan (Pamukkale benzeri) teras tipi travertenler ile Çamlık Köy'ünde bulunan sırt tipi travertenlerdir (Şekil 3). Bu çalışmada, genç volkanizma, aşınma süreçleri ve traverten çökelimi ile ilişkili jeomorfolojik yapılar detaylandırılacaktır.

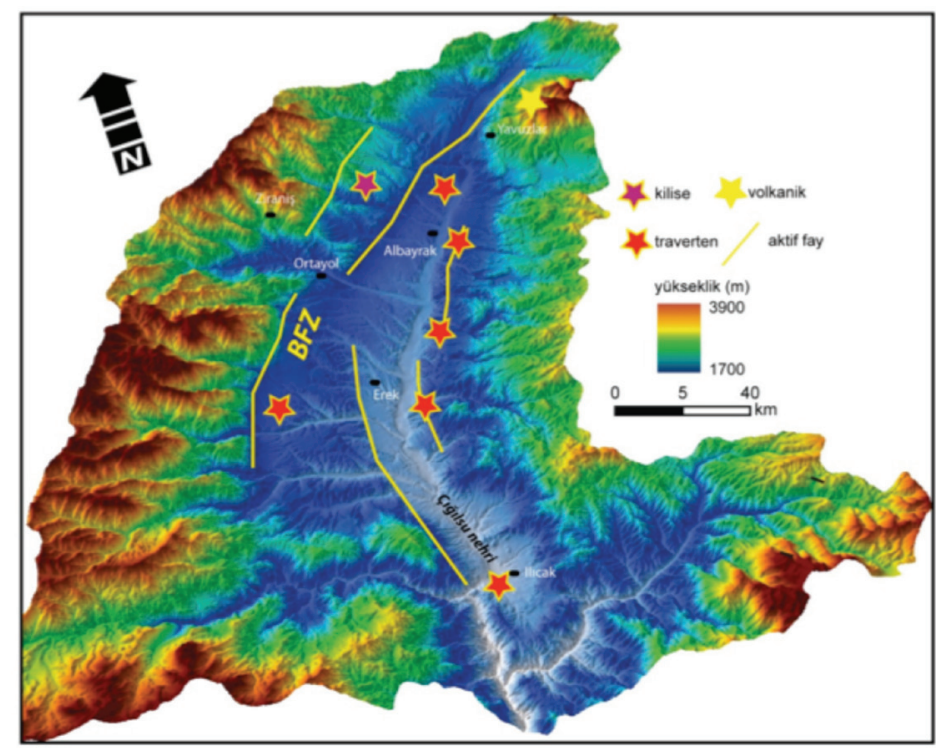

Şekil 2. Başkale Bölgesi’nin yükseklik modeli ve civarında yer alan jeomorfolojik yapılar.

Figure 2. The digital elevation model of Başkale Region and geomorphological structures 

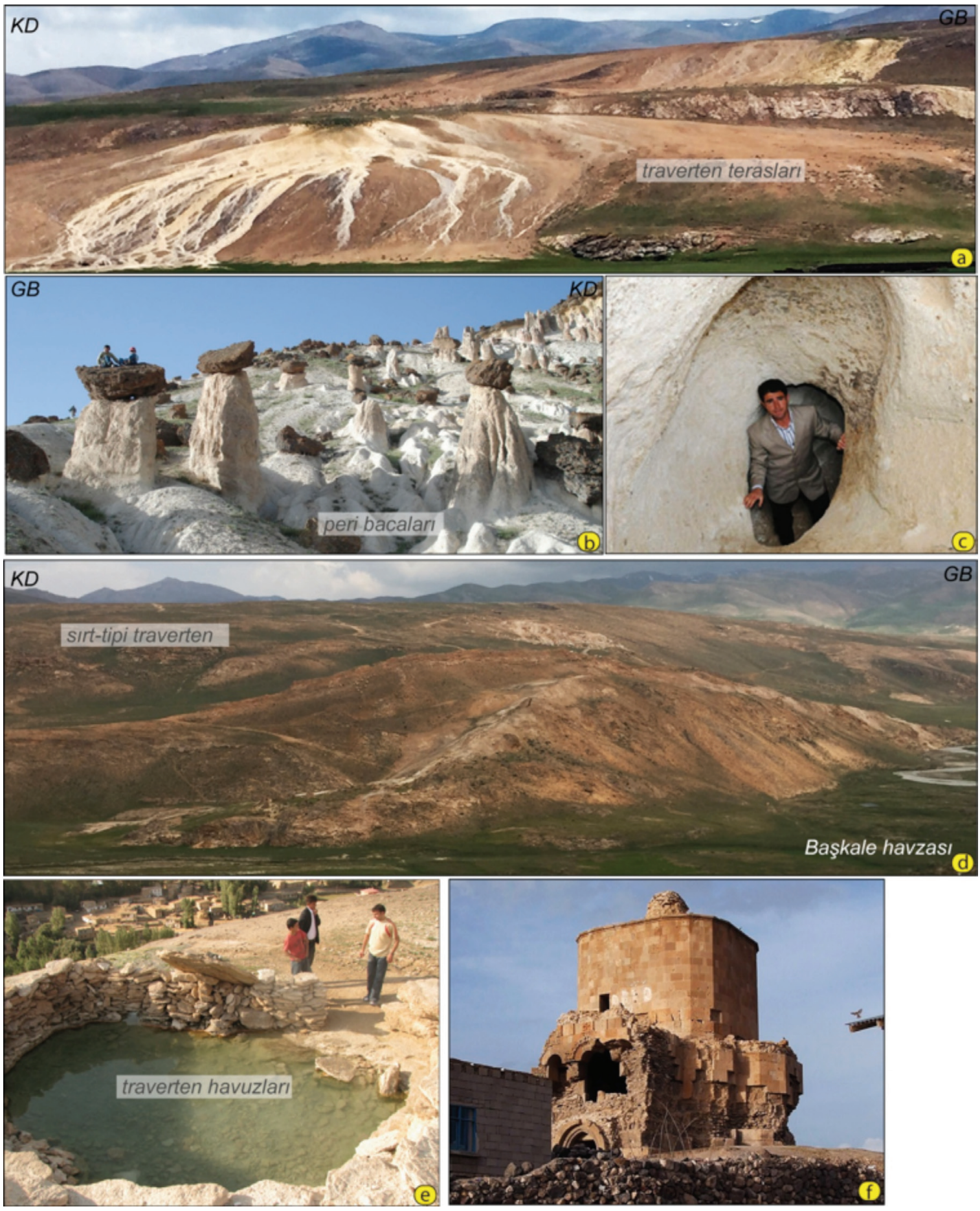

Şekil 3. a) Albayrak Köyü civarında yer alan traverten terasları, b) Yavuzlar Köyü civarında yer alan peribacaları, c) bölgede yer alan mağaralar, d) Mahmutalan Köyü civarında yer alan sırt-tipi travertenler, e) traverten havuzları, f) MS 7-9. yy'a tarihlenen St Ejmiacin (Soradir) kilisesi.

Figure 3. a) The travertine terraces situated near the village of Albayrak, b) the fairy chimneys at the Yavuzlar Village, c) caves in the region, d) the fissure-ridge travertine at the Mahmutalan Village, e) travertine pool, f) St Bartholomeus church constructed at 13th century AD. 


\section{JEOLOJİ VE STRATIGRAFI}

Türkiye-İran sınırında yer alan çalışma alanında, plütonik, volkanik, metamorfik, sedimanter ve ofiyolit kökenli kaya birimleri yüzeylenir. Başkale Havzasinda birbirlerinden uyumsuzlukla ayrilan üç temel jeolojik birim ayırt edilebilir: (1) Baskın olarak mermer ve şistlerden oluşan metamorfik kayaçlar, (Yılmaz, 1971; Ricou, 1971; Yılmaz, 1975; Erdoğan, 1975, Göncüoğlu ve Turhan, 1984); (2) Neojen karasal sedimanter ve volkanik kayaçlar (gölsel kireçtaşları, kumtaşları ve bazalttüf); (3) Kuvaterner alüvyal, flüvyal ve kolüvyal çökeller ile traverten oluşumları. Havza içerisinde yer alan birimlerin arasındaki dokanak genel olarak fay kontrollüdür. Kuvaterner çökelleri havza dolgusunu oluştururken, metamorfik kayaçlar havzanın batı, volkanik kayaçlar ise genel olarak doğu kenarında yer almaktadır (Şekil 4a).

Bölgede yer alan volkanik kayaçlar Türkiye-İran sınırında bulunan Yiğit Dağı Volkanına ait ürünlerdir (Sümengen, 2008). Bunlar genel olarak bazalt ve piroklastik kayalarla temsil edilir. Piroklastik kayalar tüf, tüfit ve ignimbritlerden meydana gelmektedirler. Beyaz, kirli sarı renkli, tabakalı ya da masif olan tüf ve tüfitler, yer yer kırıntılı kayalarla yanal geçiş gösterir. Volkanik istifin üst seviyelerinde bazaltlar yer alır ve değişik kalınlık ve boyutlarda, plakalı, yer yer akıntı yapılı, gözenekli bir yapı sunarlar (Sümengen, 2008) (Şekil 4b).

Başkale Havzası'nın doğu ve batı kenarını sınırlayan faylar boyunca traverten çökelleri geniş bir alanda yüzeylemektedir. Travertenler genel olarak ayrışma rengi koyu sarı, taze yüzeyi sarı, bej renkli, orta-kalın, tabakalı, sert, sık1 tutturulmuş, erime yüzeyli ve boşlukludur. Havza dolgusunu, göl ve akarsu ortamında çökelmiş kumtaşı-silttaş1çakıltaşlarından oluşan Büyükçay Formasyonu oluşturmaktadır (Acarlar ve Türkecan, 1986).

\section{Vanadokya Volkanik Alanı (VVA)}

Van'ın Başkale İlçesine bağlı Yavuzlar Köy'ünde bulunan kırgı bayırı topoğrafyasında gelişmiş peri bacalarına yöre halkı tarafindan "Vanadokya" ismi verilmiştir (Şekil 2). Pliyo-Kuvaterner yaşlı Yiğit Dağ1 volkanizmasının ürünlerinin farklılaşmış aşınımı sonucu gelişen peribacaları, jeolojik ve jeomorfolojik koşulların ortak işlevleri sonucu meydana gelmiştir. Bu yapılar genel olarak tüf, tüfit ve ignimbrit ardalanmasından oluşan bir serinin üzerinde yer alırlar. İnceleme alanı içerisinde $55 \mathrm{~km}^{2}$ alan içerisinde yaklaşık 17000'den fazla peribacası ile birlikte 35 mağara ve 12 oyma kaya evi bulunduğu bilinmektedir (İHA). Bunlar genel olarak şapkalı, sütunlu ve sivri tiplerdir (Şekil 5). 


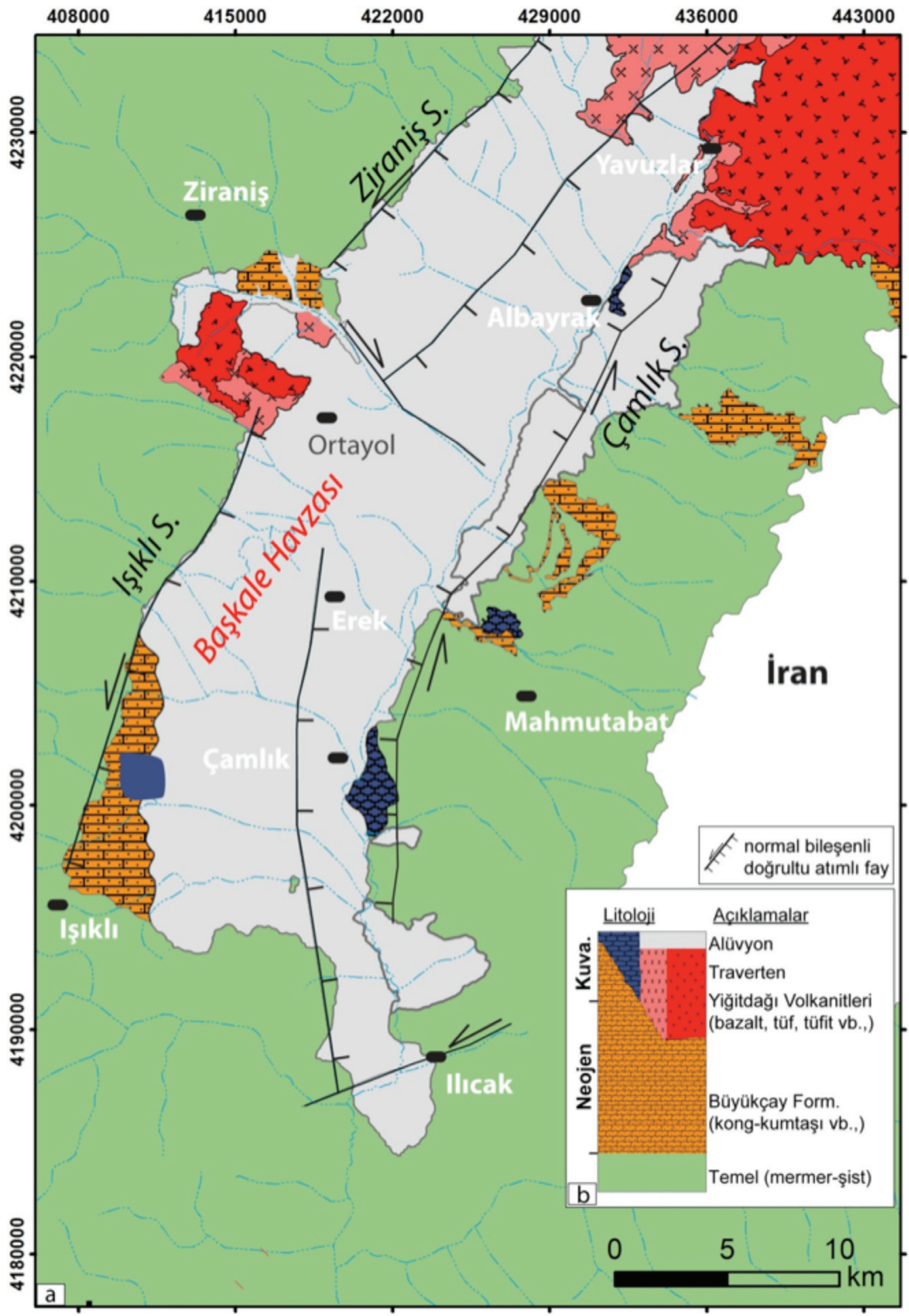

Şekil 4. a) Başkale Bölgesinin jeoloji haritası (Ateş vd., 2007'den değiştirilerek alınmıştır), b) Van Gölü güneyinin stratigrafik istifi (Sümengen, 2007).

Figure 4. a) The simplified geological map of Başkale region (modified after Ateş et al., 2007), b) the stratigraphic sequence of the Van Lake South (Sümengen, 2007). 
Peribacaları, koni şeklinde olup, bloğun yalnızca ignimbritlerden oluşmasıdır. çoğunlukla tipik bir peribacası morfolojisine sahiptir. Bir gövde ile çoğunlukla tepe kısmında bulunan bir bloğun oluşturduğu takke olmak üzere iki kısımdan oluşur. Çalışma alanı içerisinde takkeyi oluşturan (ignimbritler) blokların çoğu düşmüştür ve gövdeleri genellikle silindirik veya konik biçimli geometri gösterirler. $\mathrm{Bu}$ durumun sıç̧a görülmesinin nedeni takkeyi oluşturan

Ayrıca inceleme alanında yamaçların üst kesimlerinde yer alan peribacalarında aşınma ve bozunma seviyesi daha azdır. Çok az eğimli ve alt bölümlerde yer alan peribacalarının yoğunluğunun azaldığg ve biçimlerinin bozulduğu görülmektedir. Bölgede, son yıllarda yağışların etkisiyle ortaya çıkan, metrelerce uzunluktaki çok sayıda tünel ve mağara da ilginç yer şekilleri arasındadır.

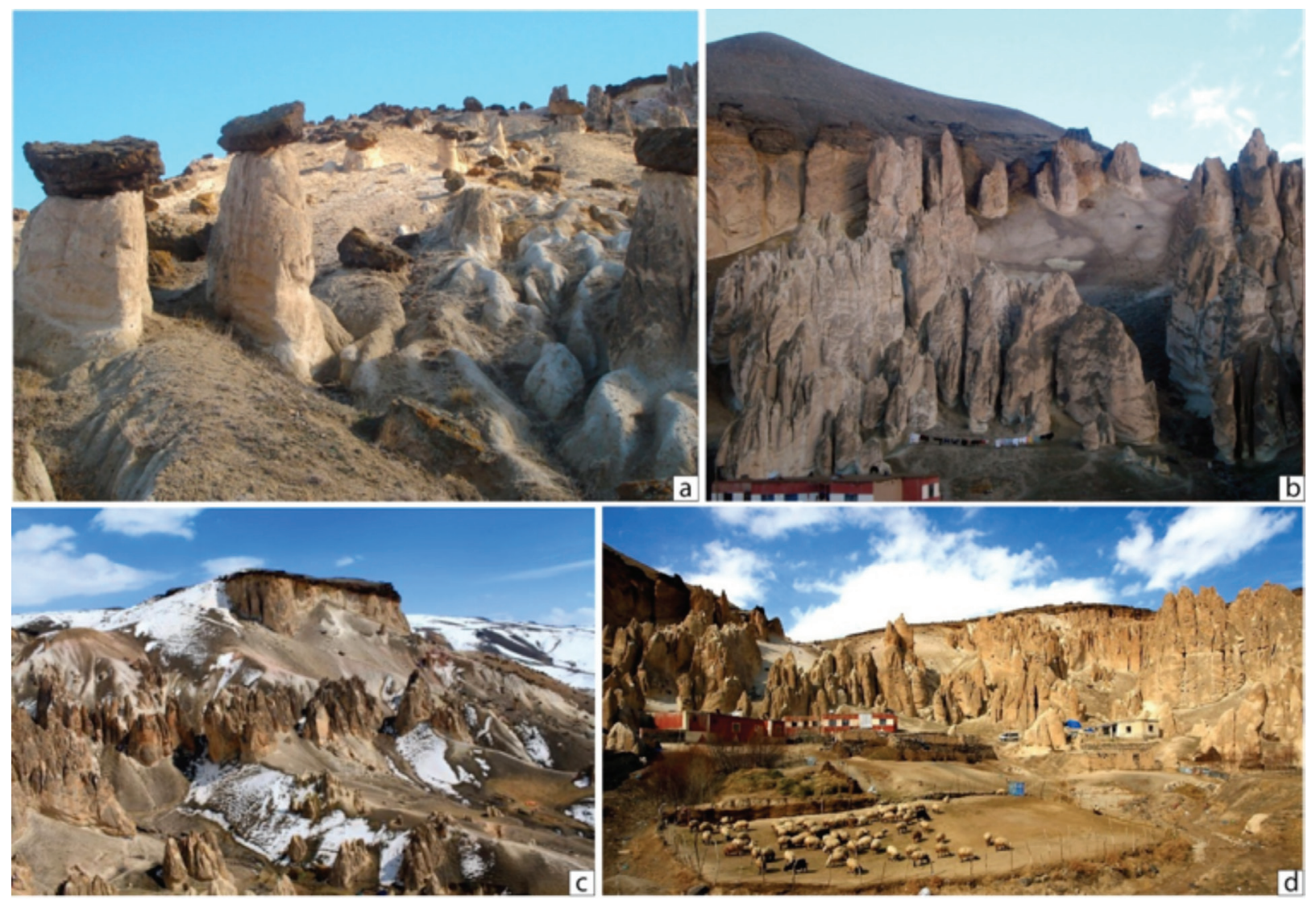

Şekil 5. Yavuzlar Köyü Vanadokya volkanik alan1, a) tipik peribacası, b) Yavuzlar Köyü doğusunun görünümü, c)-d) volkanik alanın kuzey ve güney görünümü.

Figure 5. Vanadocia Volcanic Area at Yavuzlar Vvillage, a) typical fairy chimneys, b) eastern view of Yavuzlar Village, c), d) north and south view of the volcanic area. 


\section{Dereiçi Travertenleri}

Van İl merkezine 150, Başkale İlçesi'ne ise 35 kilometre uzaklıkta bulunan Dereiçi Köyü'nün batısında yaygın traverten oluşumları gözlenmektedir. Yaklaşık $2 \mathrm{~km}^{2}$ 'lik alanda yer alan Dereiçi travertenleri, havzayı batıdan sınırlayan BFZ'nin tavan bloğu üzerinde yer almaktadır (Şekil 2). Aktif traverten oluşumları günümüzde havza içerisinde devam etmektedir. Teras tipi travertenlerden oluşan Dereiçi travertenleri, havzanın batısında yer alan kaynaklardan çıkan suyun yamaç aşağı akmasıyla oluşmuşladır.

Teras tipi travertenlerin güney kısmı genel olarak beyaz ve kirli beyaz renkte görülmektedir
(Şekil 6 a,b). Halen aktif olarak beslenen ve depolanmaya devam eden güney k1sımda su Sıcaklığ $130-35^{\circ} \mathrm{C}$ arasındadır. Kuzey kesimi besleyen aktif su kaynaklarının kimyasının güneye göre daha farklı olduğu çökelen travertenlerden anlaşılmaktadır (Şekil 6d). Kuzey kesim kırmızısarı renkli travertenlerden meydana gelmektedir. Eğimli bir yamaç boyunca yer alan teras tipi travertenler, boyutları santimetreden metreye varan traverten havuzları ve terasları içerirler. Üst kısımlarda daha geniş traverten havuzları bulunurken, alt kesimlerde daha küçük havuzlar bulunmaktadır (Şekil6 b, d). Bunun nedeninin suyun alt kesimlerde kısmen soğuması ile ilişkili olduğu söylenebilir (Weed, 1989; Altunel 1996).
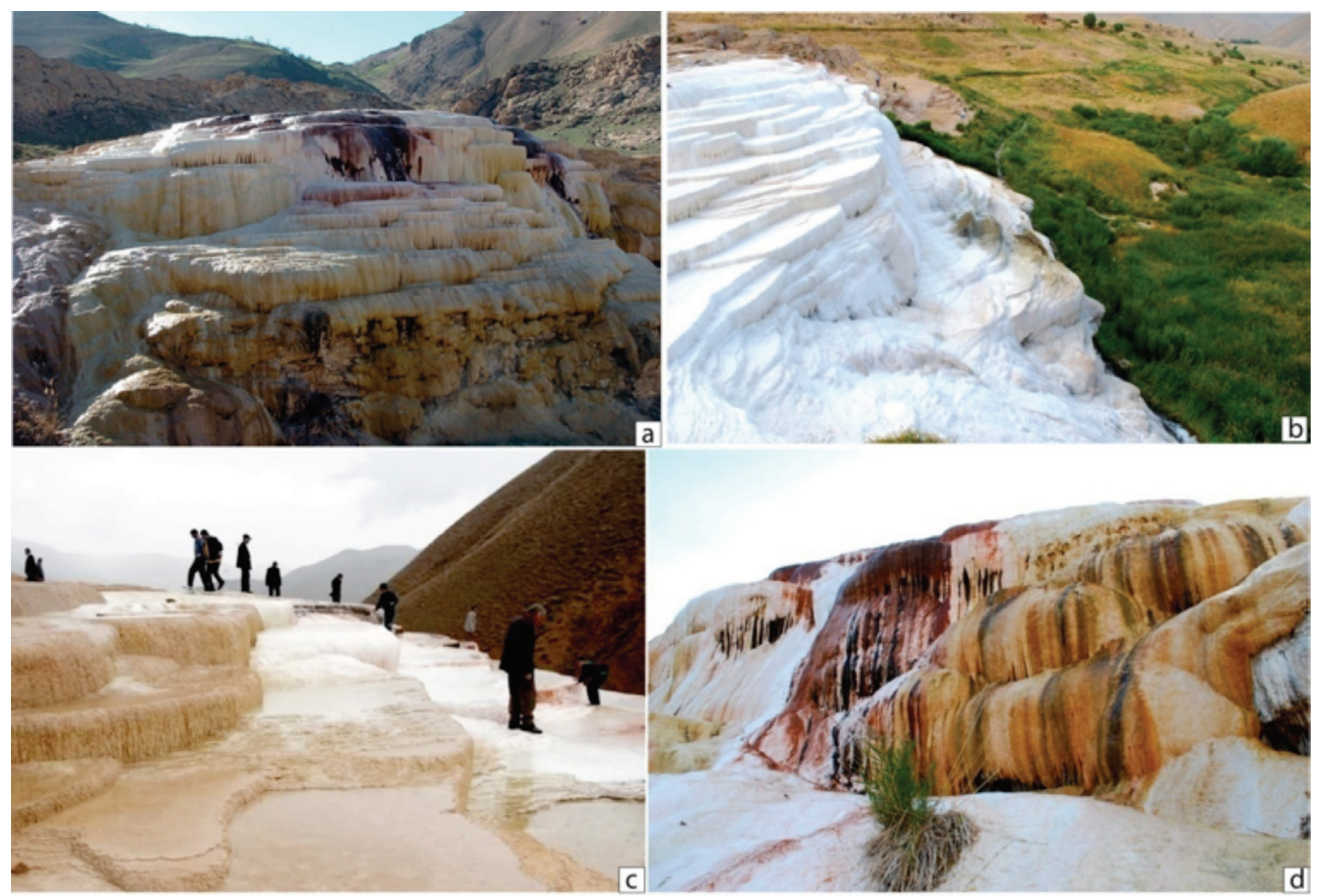

Şekil 6. Dereiçi Köyü travertenleri, a) travertenlerin güneyden görünümü b) kuzeyden görünüm, c) traverten havuzları, d) güncel traverten oluşumları (fotoğraflar: Osman Ünlü).

Figure 6. Travertine of Dereiçi Village, a) the south view of travertine b) the north view of travertine, c) travertine pool, d) active travertine formation (photos: Osman Ünlü). 


\section{Başkale Sırt Tipi Travertenleri}

Fay, çatlak veya yarık hattı boyunca yüzeye çıkan yeraltı sularının, bu tektonik yapıların içinde veya yeryüzüne çıktıkları yerde, yapının her iki tarafında kalsiyum karbonatın üst üstte birikmesi ile oluşmuş, enine kesitleri çatı biçiminde, uzun eksenleri antiklinal şeklinde olan jeomorfolojik yapılar sırt tipi traverten olarak adlandırılmaktadır (Bargar, 1978; Chafetz ve Folk, 1984; Altunel ve Hancock, 1993a,b, 1996; Çakır, 1999; Hancock vd., 1999; Uysal vd., 2009; De Filippis vd., 2012).
$\mathrm{K} 30^{\circ} \mathrm{B}$ ile $\mathrm{K} 45^{\circ} \mathrm{B}$ arasında ve açıklığ 1 ise $90 \mathrm{~cm}$ ile $120 \mathrm{~cm}$ arasında değişmektedir (Şekil 8). Tabakalı travertenlerin farklı renk ve dokuya sahip olmaları, sırt tipi travertenin oluşumu esnasında meydana gelen mevsimsel değişimleri karakterize etmektedir. Çünkü bu ardalanım sistematik olarak devam etmekte herhangi bir zon seviyesi olarak bulunmamaktadır.

Yaklaşık $1 \mathrm{~km}$ uzunluğunda olan 2 nolu traverten $\mathrm{K} 50^{\circ}-60^{\circ} \mathrm{B}$ arasında açılma çatlağ doğrultusuna sahiptir. Sırt tipi travertenin genişliği uç kısımlarda $3 \mathrm{~m}$, orta kesimlerde

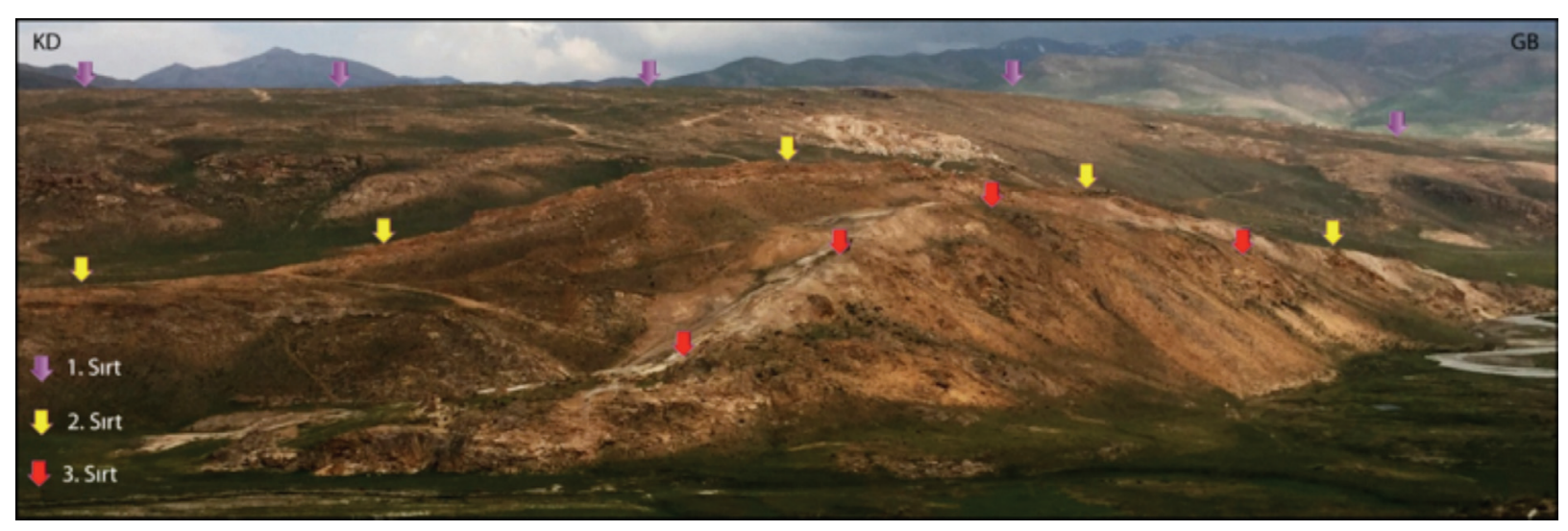

Şekil 7. Başkale sırt tipi travertenleri.

Figure 7. The fissure-ridge travertine of Başkale .

Başkale travertenleri, birbirine yaklaşık olarak paralel uzanan üç farklı sırt tipi travertenden meydana gelmektedir. Açılma çatlaklarının doğrultuları $\mathrm{K} 45-80^{\circ} \mathrm{B}$ arasında değişmektedir (Şeki17). En doğu kesimde bulunan 1 nolu traverten en üst kotta yer almaktadır ve görece en yaşlıdır, morfolojik özelliklerini korusa da günümüzde aktif değildir. Yaklaşık olarak 3 km uzunluğunda ve 12 $\mathrm{m}$ genişliğe sahiptir. Açılma çatlağının doğrultusu ise 5-6 m arasında değişmektedir. Günümüzde oniks ocağ 1 olarak işletilen bu kesim, travertenin doğu bloğu olup, tabakalı travertenler net olarak izlenmektedir. Açılan kesimde bantlı travertenler görülmemekle birlikte tabakalı travertenlerin kalınlığg 6 m civarındadır. 

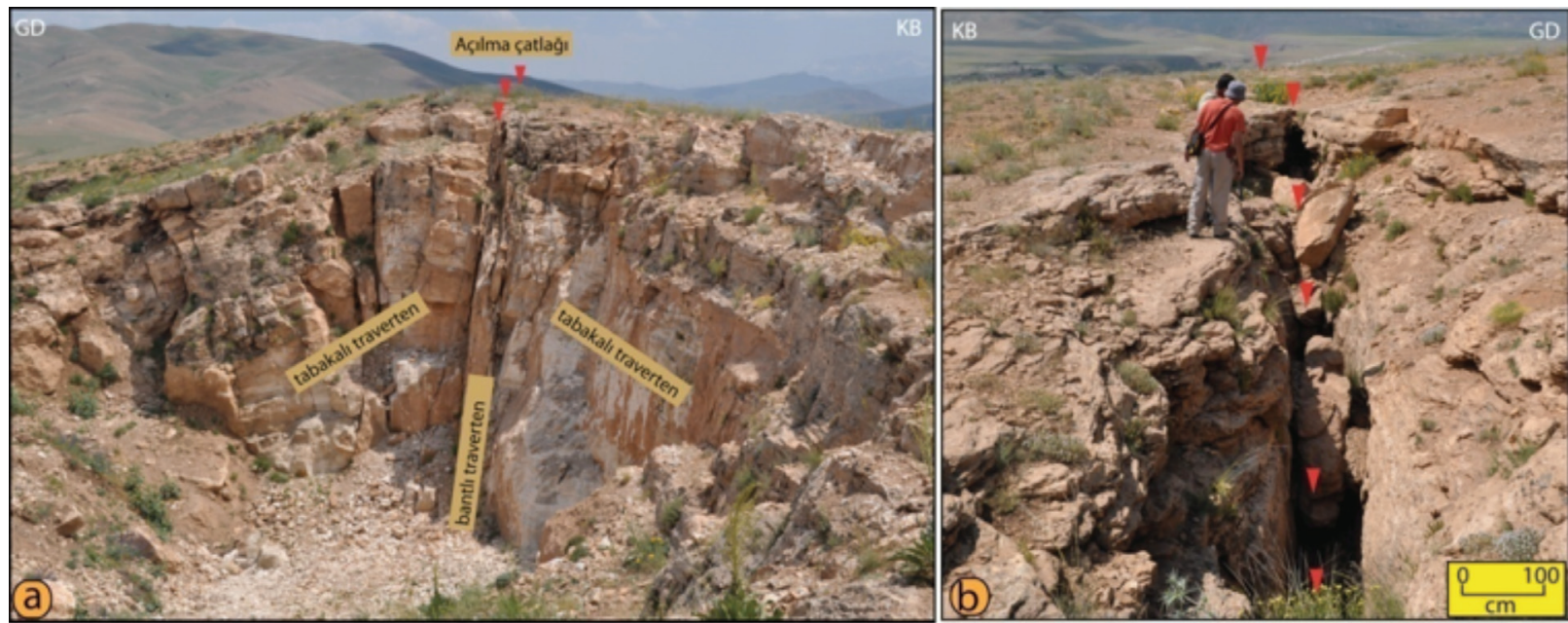

Şekil 8. a) 1 nolu sırt-tipi travertenin enine kesit görüntüsü, b) açılma çatlağı.

Figure 8. a) cross-sectional view of the ridge-type travertine, b) open fracture.

2014 y1lına kadar aktif olan 3 nolu traverten sırtı yaklaşık $800 \mathrm{~m}$ uzunluğunda $3 \mathrm{~m}$ genişliğindedir. Doğal görünümü ve yamaçlarındaki aktif traverten oluşumları ile bölgedeki en genç sirt tipi travertendir (Şekil 9a, b). Açılma çatlağının doğrultusu yaklaşık $\mathrm{K} 70^{\circ}-80^{\circ} \mathrm{B}$ arasında değişmektedir. Açılma çatlağı yaklaşık 20-40 cm arasında değişen genişliklere sahiptir. Sırt boyunca açılma çatlağında meydana gelen yer değiştirmeler sırtın bölgedeki deformasyondan etkilendiğini göstermektedir (Şekil 9c). Sırtın üzerinde travertenlere özgü olarak gelişen havuzlar da bulunmaktadır. Bu traverten havuzları 2010 y1lında aktif olarak beslenmekteyken, 2015 yılında bazı havuzların kuruduğu gözlenmiştir.

Başkale havzasının yeni sırt tipi travertenlerin oluşumu aktif olarak sürmektedir (Şekil 9d). Bölge morfolojisinin sunduğu doğal ve yapay kesitler sırt tipi travertenlerin nasıl oluştuğu hakkında ön bilgiler sunmaktadır. Bu morfolojik yapılar üzerinde oniks ocağı olarak işletilmek üzere farklı noktalarında ocaklar açılmıştır. 

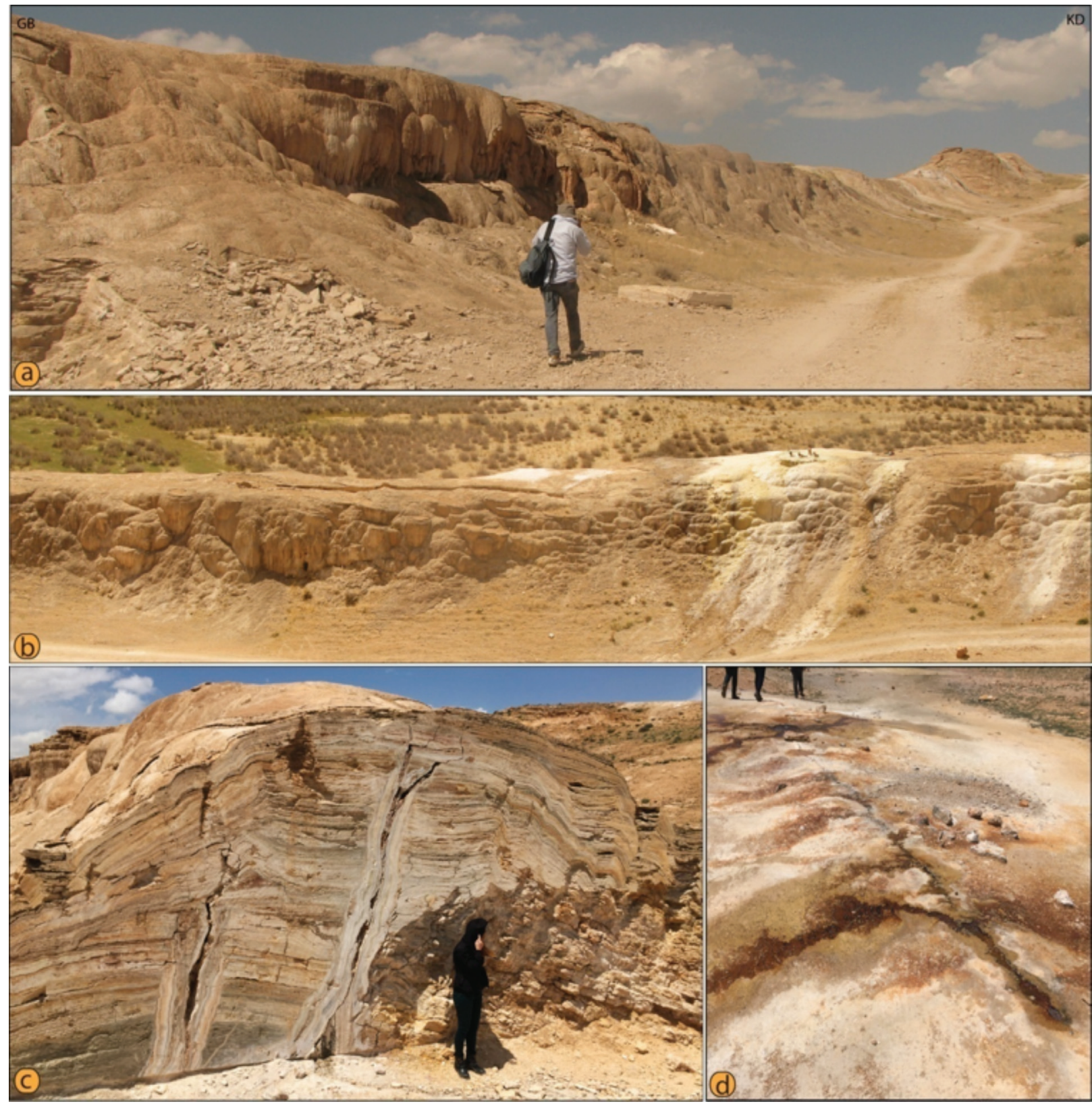

Şekil 9. 3 nolu sırt-tipi traverten. a)sırt tipi kuzey kesiminin görünümü, b) güney görünümü, c) 3. Nolu sirtın enine kesiti, d) yeni oluşmaya başlayan sırt-tipi traverten.

Figure 9. The fissure ridge travertine a) view of the northern part of the ridge, b) view of southern part, c) The cross section of the ridge, d) beginning to newly formed fissure ridge type travertine. 


\section{Kültürel Miras}

Van Bölgesindeki en eski medeniyet M.Ö. 4000 yıllarına kadar gitmektedir. Medeniyetlerin bölgede bıraktıkları etkilerin izleri halen devam etmektedir. $\mathrm{Bu}$ izlerden bazılarına Başkale Bölgesinde rastlamak mümkündür. Bunlardan bazıları St Bartholomeus ve Soradir kilisesidir.

St Bartholomeus manastırı (Surb Barduğimeosi vank), Başkale ilçesine bağlı Albayrak Köy'ünde bulunmaktadır. Büyük Zap vadisine bakan bir tepe üzerine kurulmuş olan kilisenin girişine bir jamatun:etrafına da papaz ve misafir odaları ile sosyal tesisler eklenerek manastır haline getirilmiştir. Ermeni kaynaklarında ilk yapının IV. yüzyılda Aziz Bartholomeos adına inşa edildiği belirtilmektedir. Ancak mimarî ve süsleme özelliklerine bakarak 13-14. yüzyıllar ocaklarından sağlandığı düşünülmektedir (Şekil 10). Günümüzde oldukça harap durumda olan kilise T.C. Kültür Bakanlığ1 Türkiye Kültür envanteri içerisinde değerlendirilmiştir ve restorasyon için ön çalışmalar başlamak üzeredir.

Soradir Kilisesi ise Başkale'nin Yanal Köyünde bulunmaktadır. St. Ejmiacin adına yapılan kilise,7-9. yüzyıllara tarihlendirilmektedir. $\mathrm{Bu}$ kilisede de yapı malzemesi olarak bölgede geniş olarak yüzeylenen travertenler kullanılmıştır.

\section{SONUÇ VE ÖNERİLER}

Van Gölü Havzasının güneybatısında bulunan Başkale Havzasında jeolojik miras kapsamında değerlendirilebilecek birden fazla jeolojik oluşum bulunmaktadır. Bölge içerisinde yer alan "Vanadokya Volkanik Alanı,
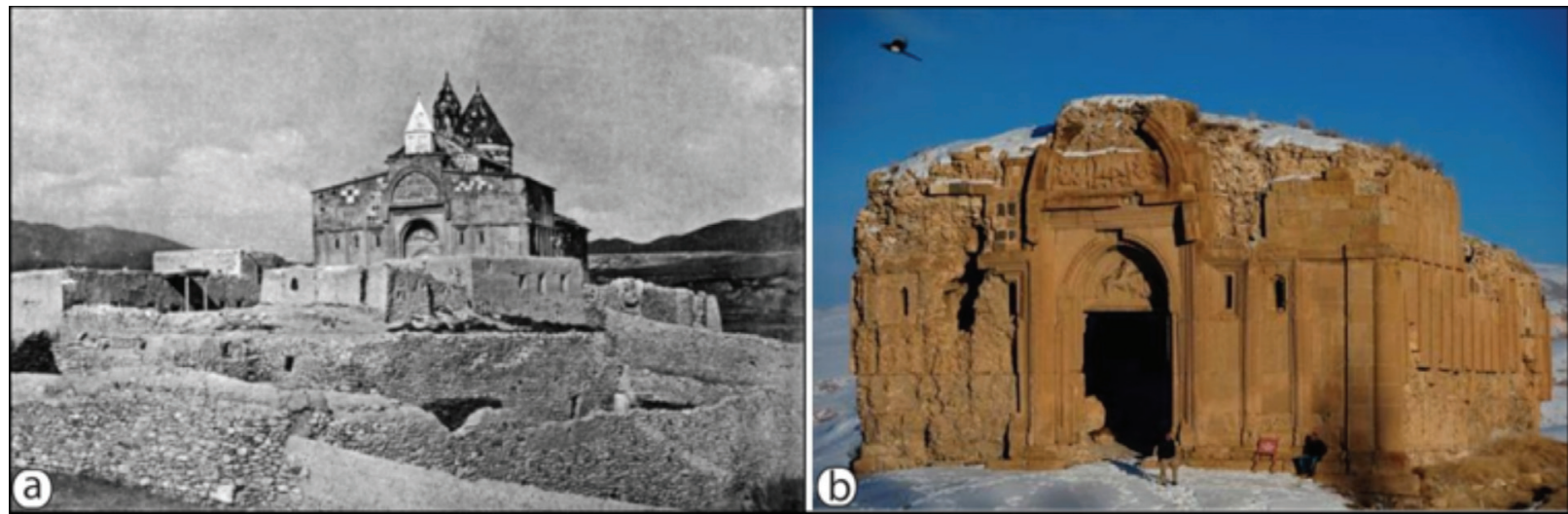

Şekil 10. a) St Bartholomeus kilisesinin 20.yy başlarındaki (Bachmann, 1913) ve b) günümüz görünümü

Figure 10. a) The early 20th century view of St Bartholomew church (Bachmann, 1913), b) today's situation

arasina tarihlendirilmektedir. Yap1 daha sonra 1647-1655,1760 ve 1877 tarihlerinde kapsamlı onarımlar geçirmiştir. Günümüze ulaşan mimarisi 17-19. yüzy1llara aittir (Bachmann, 1913; Cirban, 2016).Manastırda yapı malzemesi olarak travertenler kullanılmıştır. $\mathrm{Bu}$ travertenlerin manastırın doğu kesiminde yer alan traverten

\section{Dereiçi Travertenleri ve Başkale Sırt Tipi} Travertenleri" en belirgin jeodeğerlerdir. Bölgede yer alan bu jeolojik oluşumların tanımlanması için detaylı araştırmalar yapılması, yerel yönetimlerle işbirliği içerisinde jeoturizm potansiyelinin ortaya konularak tanıtılması gerekmektedir. 
"Vanadokya" bölgesindeki oluşumların dağılımı ve niteliği bir jeoturizm potansiyeli içermektedir. Peribacaları, mevcut doğal ve antropojenik süreçler nedeniyle hızla tahrip olmaktadır. Bölgenin mevcut koruma kanunları (tabiat anıtı, doğal sit) kapsamı içerisinde ve yerel yönetimlerin farkındalığının arttırılarak jeopark statüsünde değerlendirilmesi önerilebilir.

Ancak, bölgede yer alan bu jeolojik oluşumların kamuoyu tarafindan fazlaca tanınmadığı ve kültürel jeoloji çerçevesinde ele alınmadıkları ortadadır. Bu bağlamda, bölgenin sürdürülebilir kalkınma projelerinde ana aktör olabilecek nitelikteki bu doğal ve kültürel varlıkların tanımlanmaları için daha ayrıntılı ve kapsamlı araştırmalar ve çalışmalar yapılması gerekir. $\mathrm{Bu}$ jeomorfolojik yapıların "jeolojik miras" kapsamına alınması ve her birinin "jeosit" özelliklerinin ortaya konması gerekmektedir.

\section{KATKI BELIRTME}

Yazarlar bu çalışmanın değerlendirme sürecindeki katkılarından dolayı Yrd. Doç. Dr. Yıldırım GÜNGÖR ve Yrd. Doç. Dr. M. Korhan ERTURAÇ'a teşekkür eder.

\section{EXTENDED SUMMARY}

Başkale Basin is located at southeast of Van City, Eastern Turkey. It extends NNE with an approximate width of $15 \mathrm{~km}$ and length of 82 km. Basskale Fault Zone (BFZ) is a N-S trending deformation area with an approximate width 12 $\mathrm{km}$ and length of $100 \mathrm{~km}$ (Koçyiğit, 2005; Emre et al., 2012). This deformation area is located in between active Şemdinli-Yüksekova Fault Zone and Gailatu-Siah Chesmeh-Khoy Fault System which strikes to WNW at south-east of Iran. There are various internal and external earth processes that control the formation of geological heritage sites at Başkale region, where some of these formations are tectonic; some of them are volcanic in origin. At the NE part of the basin, various types of travertine formations occur. Terrace travertines are located at Dereiçi village with spectacular travertine pools and ridge type travertine which are located at Çamlık village.

Vanadocia name is given by community to the fairy chimneys within the local bad land topography at Yavuzlar Village. These structures are formed on the pyroclastics of Yiğit Volcano of Plio-Quaternary age and which covers an area of $55 \mathrm{~km}^{2}$. There are about 1700 fairy chimneys of capped, columns and pointed types. There are also numerous tunnels and caves within these pyroclastics. Dereiçi travertines are located at the west of Dereiçi village covering $2 \mathrm{~km}^{2}$ areas. Recent hot springs cause terrace type travertine formations forming pools. To the southwest of the basin, there are three distinct ridge type travertine formations where the youngest is still active. These formations are observed at around Çamllk Village.

These geosites within the Başkale Basin can be evaluated and valued within the context of geological heritage. This can be realized by coordination of the local authorities and the citizens aided by earth scientists.

\section{DEĞIINILEN BELGELER}

Acarlar, M., Türkecan, A., 1986. Başkale (Van) Batı ve Kuzeybatısının Jeolojisi. MTA Rapor No: 7913, 87s (yayınlanmamış).

Altunel, E. 1996. Pamukkale Travertenlerinin morfolojik özellikleri, yaşları ve neotektonik önemleri. MTA Dergisi, 118, 47-64. 
Altunel, E., Hancock, P.L. 1993a. Active fissuring and Faulting in Quaternary travertines at Pamukkale, Western Turkey. Zeitschrift für Geomorphologie Supplement, 94, 285-302.

Altunel, E., Hancock, P.L. 1993b. Morphology and structural setting of Quaternary travertines at Pamukkale, Turkey. Geological Journal, 28, 335346.

Altunel, E., Hancock, P.L. 1996. Structural attributes of travertine filled extensional fissures in the Pamukkale Plateau, Western Turkey. International Geology Review, 38, 768-777.

Ateş, Ş., Mutlu, G., Özerk, O.Ç., Çiçek, İ., Karakaya Gülmez, F., Bulut Üstün, A., Karabıyıkoğlu, M., Çelebioğlu, R., Özata, A., \& Aksoy, A., 2007. Van Bölgesinin yerbilimleri verileri. MTA Rapor No:10961, 152s (yayınlanmamış).

Bachmann, W., 1913. Churches and mosques in Armenia. 80 p. front. (map) illus., 71 pl. (2 double) incl. plans. $37 \mathrm{~cm}$, Leipzig.

Bargar, K. E., 1978. Geology and thermal history of Mammoth Hot Springs, Yellowstone National Park, Wyoming. U.S. Geological Survey Bulletin, 1444, 1-55.

Chafetz, H.S., Folk, R.L. 1984. Travertines: Depositional morphology and the bacterially constructed constituents. Journal of Sedimentary Petrology, 54, 289-316.

Çakır, Z., 1999. Along-strike discontinuity of active normal Faults and its influence on Quaternary travertine deposition; examples from western Turkey. Turkish Journal of Earth Sciences, 8, 6780.

De Filippis, L., Faccenna, C., Billi, A., Anzalone, E., Brilli, M., Özkul, M., Villa, I. M. 2012. Growth of fissure ridge travertines from geothermal springs of Denizli basin, western Turkey. Geological Society of America Bulletin, 124, 1629-1645.

Dewey, J.F., Hempton, M.R., Kidd, W.S.F., Saroglu, F.,
Şengör, A.M.C., 1986. Shortening of continental lithosphere: The neotectonics of Eastern Anatolia - A young collision zone. Geological Society Special Publication, pp. 1-36.

Djamour, Y., Andrnant, P., Nankali, H.R., Tavakoli, F., 2011. NW Iran-eastern Turkey present-day kinematics: Results from the Iranian permanent GPS network. Earth and Planetary Science Letters, 307, 27-34.

Emre, Ö., Duman, T.Y., Özalp, S., Olgun, Ş. ve Elmacı, H., 2012. 1:250.000 ölçekli Türkiye diri fay haritalar1 serisi, Van (NJ38-5) Paftas1, Seri No:52, Maden Tetkik ve Arama Genel Müdürlüğü, Ankara-Türkiye.

Erdoğan, T., 1975. Gölbaşı Civarının Jeolojisi. TPAO Raporu, 929, 18.

Göncüoğlu, M. C. ve Turhan. N. 1984. Geology of the Bitlis metamorphic belt. MTA yayınları (In: Tekeli, O. ve Göncüoğlu, M.C. (eds), 237-244.

Gürsoy, H., Tatar, O., Piper, J.D.A., Heimann, A., Koçbulut, F. and Mesci, B.L. 2009. Palaeomagnetic study of Tertiary volcanic domains in Southern Turkey and Neogene anticlockwise rotation of the Arabian Plate. Tectonophysics, 465, p.114-127.

Hancock, P.L., Chalmers, R.M.L., Altunel, E., Çakır, Z. 1999. Travitonics: using travertines in active Fault studies. Journal of Structural Geology, 21, 903-916.

İHA (İhlas Haber Ajans1), 2012. http://www.haberturk. com/ekonomi/turizm/haber/731542-vanadokyakapadokya-degil-galeri, 6 Nisan 2012.

Koçyiğit, A., Yılmaz, A., Adamia, S., Kuloshvili, S., 2001. Neotectonic of East Anatolian Plateau (Turkey) and Lesser Caucasus: Implication for transition from thrusting to strike-slip faulting. Geodinamica Acta, 14, 177-195.

Koçyiğit, A., 2005. Sütlüce (Hakkari) Depreminin Kaynaği: Başkale Fay Kuşağı, (GD Türkiye). Deprem Sempozyumu, Denizli, 1-2. 
Reilinger, R., McClusky, S., Andrnant, P., Lawrence, S., Ergintav, S., Cakmak, R., Ozener, H., Kadirov, F., Guliev, I., Stepanyan, R., 2006. GPS constraints on continental deformation in the Africa- ArabiaEurasia continental collision zone and implications for the dynamics of plate interactions. Journal of Geophysical Research: Solid Earth (1978-2012) 111.

Ricou, L. 1971. Le croissant ophiolitique péri-arabe: Une ceinture de nappes mises en place au Crétacé supérieur.

Sümengen, M., 2008. Başkale-L52 paftası:Türkiye 1/100.000 ölçekli jeoloji haritaları serisi, MTA yayınları, Ankara.

Şaroğlu, F., Yılmaz, Y., 1986. Doğu Anadolu'da neotektonik dönemdeki jeolojik evrim and havza modelleri. Maden Tektik ve Arama Dergisi, 107, 73-94.

Şengör, A. M. C., ve Kidd, W. S. F., 1979. Postcollisional tectonics of the Turkish-Iranian plateau and a comparison with Tibet. Tectonophysics, 55(3-4), 361-376.

Şengör, A. M. C., ve Yılmaz, Y., 1981. Tethyan evolution of Turkey: A plate tectonic approach. Tectonophysics, 75(3-4), 181-190,193-199,203241.
Uysal, I.T., Feng, Y., Zhao, J.X., Isik, V., Nuriel, P., Golding, S.D., 2009. Hydrotermal CO2 degassing in seismically active zones during the Late Quaternary. Chemical Geology, 265, 442-454.

Yılmaz, Y., 1971. Etüde petrographicque et geochronologique de la region de Casa (Partie Meridionale du Masif de Bitlis, Turquie, These de doct 3 cycle). Univ. Sci.Med. Greonable, 230.

Yılmaz, Y., Şaroğlu, F., Güner, Y., 1987. Initiation of the neomagmatism in East Anatolia. Tectonophysics 134, 177-199.

Yılmaz, O., 1975. Casas Bölgesi (Bitlis Masifi) kayaçlarının petrografik ve stratigrafik incelenmesi. Türkiye Jeoloji Bülteni, 18-1, 33-40.

Weed, W.H., 1889. Formation of travertine and siliceous sinter by the vegetation of hot springs. U.S. Geol. Surv. Annual Rep., 9, 613-676.

\begin{tabular}{lll}
\hline Makale Geliş Tarihi & $:$ & 24 Eylül 2016 \\
Kabul Tarihi & $:$ & 24 Kasım 2016 \\
& $:$ & \\
Received & 24 September 2016 \\
Accepted & $:$ 24 November 2016
\end{tabular}


